\title{
In Vivo and In Vitro Effects of a HIF-1 $\alpha$ Inhibitor, RX-0047
}

\author{
Z. Gunnur Dikmen, ${ }^{1,2 *}$ Ginelle C. Gellert, ${ }^{2}$ Pakize Dogan, ${ }^{1}$ Heejeong Yoon, ${ }^{3}$ Young Bok Lee, ${ }^{3}$ \\ Chang Ho Ahn, ${ }^{3}$ and Jerry W. Shay ${ }^{2}$ \\ ${ }^{1}$ Department of Biochemistry, Faculty of Medicine, University of Hacettepe, 06100 Sihhiye, \\ Ankara, Turkey \\ ${ }^{2}$ Department of Cell Biology, University of Texas Southwestern Medical Center, \\ 5323 Harry Hines Boulevard, Dallas, Texas 75390-9039 \\ ${ }^{3}$ Rexahn Pharmaceuticals, Inc., Rockville, Maryland 20850
}

\begin{abstract}
HIF-1 $\alpha$ plays a major role in activating gene transcription and is important for maintaining homeostasis under hypoxic conditions. Since tumors are often in a hypoxic state, HIF- $1 \alpha$ is a potential target for the development of novel cancer therapeutics. This study was performed to determine the antitumoral efficacy of an antisense HIF- $1 \alpha$ inhibitor, RX-0047 on different human cancer cell lines (MDA-MB 231, HME50-T, PC-3, Panc-1 and A549) in vitro. A549 lung cancer and PC-3 prostate cancer cells containing a luciferase gene reporter were used for in vivo xenograft animal models. Progressive tumor development was quantified using live animal BLI (bioluminescence imaging) in addition to ex vivo imaging and histology. All cell lines tested were sensitive to inhibition of cell growth with $10 \mathrm{nM}$ and higher ranges of RX0047, additionally RX-0047 sensitizes cells to ionizing radiation treatments. Finally, RX-0047 (30 mg/kg) inhibited the formation of human lung metastasis in xenograft mouse models and reduced tumor size in flank models. J. Cell. Biochem. 104: 985-994, 2008. (c) 2008 Wiley-Liss, Inc.
\end{abstract}

Key words: hypoxia; HIF-1 $\alpha$; RX-0047; cancer; bioluminescence imaging

The hypoxia-inducible factors (HIFs) are key transcriptional regulators of the hypoxic response in both adult and embryonic organisms. HIF-1 regulates cellular adaption to oxygen deficiency by regulating genes involved in erythropoiesis, iron metabolism, glycolysis, angiogenesis, inhibition of apoptosis, tissue matrix metabolism, cell proliferation and survival, which are key factors for tumor growth [Semenza, 2002; Bracken et al., 2003; Goda et al., 2003]. Loss of HIF- $1 \alpha$ activity dramati-

Grant sponsor: Harold Simmons Cancer Center; Grant sponsor: UT Southwestern/MD Anderson Lung SPORE; Grant number: CA70907; Grant sponsor: Cancer Imaging Program P20 (pre-ICMIC); Grant number: CA 86354.

*Correspondence to: Z. Gunnur Dikmen, Department of Biochemistry, Faculty of Medicine, University of Hacettepe, 06100 Sihhiye, Ankara, Turkey.

E-mail: gunnur@hacettepe.edu.tr

Received 21 October 2007; Accepted 4 December 2007

DOI 10.1002/jcb.21681

(c) 2008 Wiley-Liss, Inc. cally decreases tumor growth, vascularization, and energy metabolism, whereas overexpression of HIF- $1 \alpha$ increases HIF-1 transcription factor activity and promotes tumor growth [Powis and Kirkpatrick, 2004].

HIF-1 is a heterodimer consisting of the oxygen sensitive HIF- $1 \alpha(120 \mathrm{kDa})$ and the constitutively expressed HIF-1 $\beta$ subunit (80 kDa) which is also known as aryl hydrocarbon receptor nuclear translocator, ARNT [Wang and Semenza, 1995]. Both subunits contain a basic-helix-loop-helix motif and a Per $\underline{\text { Arnt }} \underline{\text { Sim }}$ (PAS) protein-protein interaction domain [Wang et al., 1995]. Recent studies demonstrated that hydroxylation of HIF- $1 \alpha$ at two specific proline residues (Pro-402 and Pro564 ) is catalyzed by prolyl-4-hydroxylase (PHD) using molecular oxygen, $\mathrm{Fe}^{+2}$ and oxoglutarate as substrates [Ivan et al., 2001]. Under normoxic conditions, the tumor suppressor von HippelLindau (VHL) protein specifically interacts with hydroxylated HIF- $1 \alpha$ and mediates the assembly of a complex that activates an ubiquitin-dependent proteasome system, therefore 
HIF- $1 \alpha$ subunit is kept low due to massive ubiquitination and subsequent proteosomal degradation [Salceda and Caro, 1997; Maxwell et al., 1999]. However, during hypoxia, proline is not hydroxylated, and ubiquitination is inhibited, causing accumulation of the HIF-1 $\alpha$ protein [Salceda and Caro, 1997; Maxwell et al., 1999; Bruick, 2003]. Stabilized HIF-1 $\alpha$ protein translocates into the nucleus and makes a heterodimer with its partner HIF-1 $\beta$. Once the HIF- $1 \alpha /$ HIF- $1 \beta$ heterodimer is formed, it binds to a 256 base-pair enhancer region called the hypoxia-response element (HRE) in a hypoxiasensitive target gene such as erythropoietin (Epo), resulting in activation [Semenza et al., 1991]. In addition to Epo, HIF-1 also binds to HREs in genes such as vascular endothelial growth factor (VEGF) and glucose transporter-1 (GLUT-1) leading to angiogenesis and glycolysis, and also plays a role in p53 accumulation, Ras pathway stimulation, nitric oxide synthase (NOS) expression and multi-drug resistance (MDR) gene expression [Semenza, 2000; Shannon et al., 2003]. Thus, the hypoxic induction and modification of HIF- $1 \alpha$ determine the HIF-1 transcription activity for adapting to hypoxia.

HIF s have been implicated in the pathophysiology of many major human diseases, including cancer, preeclampsia, pulmonary hypertension, myocardial and cerebral ischaemia [Semenza, 2000]. Zhong et al. [1999] provided the first clinical evidence supporting the role played by HIF-1 in human cancer progression. The overexpression of one or both HIF- $1 \alpha$ proteins has been found in invasive bladder cancer, brain tumors, breast cancer, cervical cancer, nonsmall-cell lung cancer, non-Hodgkin's lymphoma, oropharyngeal cancer, pancreatic cancer and numerous other tumors including colon, skin, gastric, prostate and renal clear cell carcinomas [Birner et al., 2000; Zagzag et al., 2000; Aebersold et al., 2001; Akakura et al., 2001; Bos et al., 2001; Giatromanolaki et al., 2001; Stewart et al., 2002; Xia et al., 2002]. Furthermore, a correlation between HIF overexpression and resistance to radiation therapy or chemotherapy leading to poor patient prognosis has been noted in many of these studies, often in concert with additional genetic alterations such as activation of oncogenes or inactivation of tumor suppressor genes [Patiar and Harris, 2006]. As HIF-1 $\alpha$ has such a major role in activating gene transcription important for maintaining homeostasis under hypoxic conditions and is clearly overexpressed in many invasive cancers, it should be an excellent target for the development of novel cancer therapeutics.

The objective of this study was to investigate the in vitro effects of an antisense oligonucleotide HIF-1 $\alpha$ inhibitor, RX-0047 (Rexahn Corporation, Rockville, MD) on different cell lines (MDA-MB 231, HME50-T, PC-3, Panc-1 and A549). In addition, we tested the anti-tumoral efficacy in xenograft animal models using bioluminescence imaging (BLI) at different times following A549-Luc (lung) or PC3-Luc (prostate) tumor cell introduction.

\section{MATERIALS AND METHODS}

\section{Cell Culture}

The A549-Luc and PC-3-Luc cancer cell lines were established by infection with a lentivirus encoding the luciferase gene driven by a ubiquitin promoter. These lentiviral expression plasmids encode for the HIV-1-Gag-pol, HIV-1reverse transcriptase, HIV-1-VSV-G envelope proteins. The $293 \mathrm{~T}$ cells were grown in DMEM plus $10 \% \mathrm{FCS}$ (Invitrogen) at $37^{\circ} \mathrm{C}, 5 \% \mathrm{CO}_{2}$. The lentiviral vectors (CW-GagPol, CMW-Rev, CMV-VSV-G) were co-transfected into 293T cells using Fugene 6 (Roche Biosciences) overnight (approximately $14-16 \mathrm{~h}$ ) at $37^{\circ} \mathrm{C}$. Viruscontaining media was collected and filtered $(0.45 \mu \mathrm{m})$ after 24,36 and $48 \mathrm{~h}$ and replaced with fresh culture medium at each time point. The A549 and PC-3 cells (ATCC) were infected with the virus-containing media supplemented with $10 \mu \mathrm{g} / \mathrm{ml}$ of DEAE-Dextran. After infection, the virus-containing media was replaced with fresh media to allow the cells to recover for $24 \mathrm{~h}$. The cells were then plated at $3 \times 10^{4}$ per $10 \mathrm{~cm}$ dish and placed under selection of G418 at $500 \mu \mathrm{g} / \mathrm{ml}$ for 2 weeks. Once the A549-Luc cells were established, the cells were cultured in F12 medium (Gibco) with $5 \%$ serum and $5 \%$ glutamine whereas the PC-3 prostate cancer cell lines was grown in T medium (Gibco) containing 5\% FBS. The H1299 lung cancer cell line, the MDA-MB-231 breast adenocarcinoma cells and the tumorigenic human mammary epithelial cells (HME 50-T) were cultured in a 4:1 mixture of Dulbecco's modified Eagle's medium and medium 199 supplemented with 10\% IronSupplemented Bovine Calf Serum (BCSS) (HyClone) and $50 \mu \mathrm{g}$ of gentamycin (Sigma). The human pancreatic adenocarcinoma cells, 
Mia, and the PANC-1 prostate cancer cells, PC3, were grown in DMEM with $10 \%$ FBS.

\section{RX-0047}

RX-0047 is a 20-mer phosphorothioate antisense oligonucleotide (ASO) that is a potent inhibitor of "Hypoxia inducible factor-1 alpha" (HIF-1 $\alpha$ ) (provided by Rexahn Pharmaceutical, Inc., Rockville, MD). It was synthesized from TriLink BioTechnologies, Inc. (San Diego, CA). RX-0047 directly inhibits HIF- $1 \alpha$ by reducing expression of its mRNA and protein. Lyopholized drug was reconstituted in distilled water to a stock concentration of $1 \mathrm{mM}$ and used for both in vitro and in vivo experiments. Sense and mismatch oligonucleotides were used to demonstrate the sequence and target specificity of RX-0047.

\section{In Vitro Studies}

The effects of the HIF-1 $\alpha$ inhibitor, RX-0047, were analyzed in various human cancer cell lines, including the lung cancer cells (A549), pancreatic cancer cells (Panc1), prostate cancer cells (PC-3) and breast cancer cells (MDA-MB231 and HME50-T). The cell lines were plated at $2.5 \times 10^{4} /$ well on 6 -well dishes 1 day prior to treatment. Cells were transfected with a dose of different concentrations of RX-0047 for $4 \mathrm{~h}$ using Lipofectamine 2000 (Invitrogen) as a transfection agent, according to manufacturer's instructions. Lipofectamine alone was used as a control. Following the $4 \mathrm{~h}$ incubation, the media containing the drug was replaced with fresh media, and cells were treated with gamma irradiation (0-8 Gy) using a J.L. Stepherd and Associates type 6810 gamma irradiator, ${ }^{137} \mathrm{Cs}$ and incubated for $72 \mathrm{~h}$.

The oxygen concentration was reduced from $21 \%$ to $\sim 3-5 \%$ by sequential replacement of the total gas in a chamber with a tri-gas mixture of $91 \%$ nitrogen, $7 \% \mathrm{CO}_{2}$, and $2 \% \mathrm{O}_{2}$ for $2 \mathrm{~min}$ at 2 psi. Cells were incubated for $72 \mathrm{~h}$ at $37^{\circ} \mathrm{C}$ in Nalgene $1 \mathrm{~L}$ (32 ounce) polymethylpentene straight-side wide-mouth jars that are stood on their heads with two holes drilled in the "bottoms" (which are now the tops). The holes (1/2 inch, drilled with a home drill-press using a flat $\frac{1}{2}$ inch wood drill bit) get sealed with silicone rubber stoppers. The lid from a $10 \mathrm{~cm}$ Petri dish serves to create a flat surface on which tissue culture plates or flasks rest [Wright and Shay, 2006]. Cells were then harvested, counted and the percent inhibition was calculated using the following calculation: $100-$ (cell count for treated cells/cell count for control cells) $\times 100$.

\section{Reverse Transcription-PCR (RT-PCR) Analysis}

The level of expression of HIF- $1 \alpha$ mRNA in cells transfected with the antisense oligonucleotides was measured by RT-PCR analysis. A standard Lipofectamine 2000 (Invitrogen) protocol was employed for transfection. Samples were taken at $2 \mathrm{~h}$ after transfection, RNA was isolated and subjected to RT-PCR analysis. A549, PC-3 and PANC- 1 cells $\left(2.5 \times 10^{5}\right.$ cells per well) on a 6 -well plate were transfected with the experimental oligonucleotides and the transfected cells were used to isolate total RNA. Total RNA was isolated by using RNASTAT kit (TEL-TEST, Inc., Friendswood, TX), RNA concentration was determined by spectrophotometer. RT reaction was carried out using M-MLV enzyme kit (Invitrogen). Five micrograms of total RNA was used to synthesize cDNA in $20 \mu \mathrm{l}$ R reaction. First-strand cDNA was synthesized by incubating total RNA, oligo $\mathrm{dT}(0.5 \mathrm{mg})$ and $\mathrm{dNTP}(0.5 \mathrm{mM})$ mixture at $65^{\circ} \mathrm{C}$ for $5 \mathrm{~min}$ and by quick-chilling on ice. Firststrand buffer, $7.4 \mathrm{mM}$ DTT and $1 \mu \mathrm{L}$ M-MLV Reverse Transcriptase (200 units) was added to the above reaction mixture and incubated at $37^{\circ} \mathrm{C}$ for $50 \mathrm{~min}$ and the enzyme inactivation was followed at $70^{\circ} \mathrm{C}$ for $15 \mathrm{~min}$. HIF- 1 cDNA synthesized by $\mathrm{RT}$ reaction was measured by PCR using Sapphire RCR mix (SuperBio, Inc., Seoul, Korea) with appropriate primers. For HIF- $1 \alpha$ mRNA detection, 5' GCACAGGCCACATTCACG $3^{\prime}$ (Seq. Id No. 5) and $5^{\prime}$ TGAAGATTCAACCGGTTTAAGGA 3' (Seq. Id No. 6) primers were used. Beta-actin was used as an internal PCR control. Primers for beta-actin were $5^{\prime}$ CCCATGCCATCCTGCGTCTG $3^{\prime}$ (Seq. Id. No. 7) and 5' ACGGAGTACTTGCGCTCAG $3^{\prime}$ (Seq. Id. No. 8). PCR products were analyzed on $1.5 \%$ agarose gel by electrophoresis.

\section{Western Blotting}

Cells were treated with an iron-chelator, deferroxiamine at $100 \mu \mathrm{M}$ final concentration for $6 \mathrm{~h}$ prior to $24 \mathrm{~h}$ post-transfection. For nuclear extract preparation, the following method was used. For $10 \mathrm{~cm}$ dish, cells were washed gently with ice-cold PBS containing $0.1 \mathrm{mM} \mathrm{NaVO}_{4}(2 \times 6 \mathrm{ml})$, resuspended with $1 \mathrm{ml}$ of ice-cold PBS with $0.1 \mathrm{mM} \mathrm{NaVO}$ (sodium orthovanadate) and centrifuged at $2,000 \mathrm{rpm}$ for $5 \mathrm{~min}$. The pellet was resuspended 
in $0.3-0.5 \mathrm{ml}$ of CE buffer, $\mathrm{pH} 7.6(10 \mathrm{mM}$ HEPES, 60 mM KCl, 1 mM EDTA, 1 mM DTT, $1 \mathrm{mM}$ PMSF, $1 \times$ protease inhibitor cocktail and $0.1 \mathrm{mM} \mathrm{NaVO}_{4}$ ) with $0.5 \% \mathrm{NP} 40$ and cells were allowed to swell on ice for $5 \mathrm{~min}$. The preparation was spun at 2,000 rpm for $5 \mathrm{~min}$. The cytoplasmic extract was removed from the pellet and transferred to a new tube. The nuclei were washed gently with $0.5 \mathrm{ml}$ of $\mathrm{CE}$ buffer without NP40. The nuclei were centrifuged as above at 2,000 rpm for $5 \mathrm{~min}$. Fifty miilliliters of NE buffer, pH 8.0 (20 mM Tris-HCl, $420 \mathrm{mM}$ $\mathrm{NaCl}, 1.5 \mathrm{mM} \mathrm{MgCl}_{2}, 0.2 \mathrm{mM}$ EDTA, $1 \mathrm{mM}$ PMSF, 25\% glycerol, $0.1 \mathrm{mM} \mathrm{NaVO}$, and $1 \times$ protease inhibitor cocktail) was added to nuclear pellet and vortexed to resuspend the pellet. The extract was incubated on ice for $40 \mathrm{~min}$ with a periodic vortexing to resuspend the pellet and the $\mathrm{CE}$ and $\mathrm{NE}$ fractions were spun at maximum speed for 15 min to pellet any nuclei. The supernatant was transferred to a new tube (soluble nuclear fraction) and stored at $-70^{\circ} \mathrm{C}$. BCA protein assay reagent (Pierce Biotechnology, Rockford, IL) was used to measure protein concentration. Crude cell extracts were used to determine HIF-1 protein expression by SDS-PAGE and subsequent Western analysis using an anti-HIF1 antibody (Transduction Labs, Lexington, KY). Anti-beta-actin antibody (Santa Cruz Biotechnology) was used as an internal control.

\section{In Vivo Studies}

A549-Luc cells were assessed for tumorigenicity in a lung experimental metastasis model and PC-3-Luc cells in a subcutaneous flank tumor model. A549-Luc and PC-3-Luc cells were grown to about $70 \%$ confluence just 1 day before injection into mice. Cells were harvested, washed in $1 \times$ PBS, and the cell viability was checked with trypan blue. The cells were diluted in $1 \times$ PBS to a final concentration of $1 \times 10^{6}$ cells $/ 100 \mu \mathrm{l}$ PBS for tail vein injection and $5 \times 10^{6}$ cells $/ 400 \mu \mathrm{l}$ PBS for flank tumor model study.

Immunodeficient mice $(\mathrm{Nu} / \mathrm{Nu} ;$ Harlan Sprague Dawley, Inc., Indianapolis, IN) were maintained in pathogen-free conditions within the animal resources center (ARC) at the University of Texas Southwestern Medical Center and treated according to ARC and IACUC guidelines. Mice were irradiated with $350 \mathrm{rad}{ }^{137} \mathrm{Cs}, 18-24 \mathrm{~h}$ before tail vein injection of A549-Luc cells $\left(1 \times 10^{6}\right)$, and were used for examining the effects of RX-0047 by BLI. All animal procedures were approved by the University of Texas Southwestern University Animal Studies Committee. For the experimental metastasis model, A549-Luc cells were implanted into eight nude mice by tail vein injection $\left(1 \times 10^{6}\right.$ cells $)$, and lung metastases were allowed to develop 10-14 days postinjection and periodically imaged by bioluminescence imaging (BLI). For the control group, four mice remained untreated, whereas four mice in the treatment group received $30 \mathrm{mg} / \mathrm{kg} /$ day, intraperitoneal injection of RX-0047 for 14 days. As the drug naturally enters the cells in vivo, it is not necessary to use lipofectamine for the xenograft animal experiments. At the end of the treatment period, RX-0047 injection was stopped and all the animals were imaged with BLI. One week after the end of the treatment, both the controls and the treatment group were sacrified following BLI. The lungs were filled with 15\% india ink from the upper the trachea and fixed in Fekete's solution (100 ml of $70 \%$ alcohol, $10 \mathrm{ml}$ of $4 \%$ formalin and $5 \mathrm{ml}$ of glacial acetic acid).

PC-3-Luc cells $\left(4 \times 10^{6}\right)$ were implanted into eight nude mice subcutaneously in each flank area for primary tumor assessment without irradiation. The control group included four nude mice without any treatment whereas four of the animals were treated with RX-0047 (30 $\mathrm{mg} / \mathrm{kg}$ ) using an Alzet osmotic pump implanted subcutaneously. This pump which has a pumping rate $0.25 \mu \mathrm{l} / \mathrm{h}( \pm 0.05 \mu \mathrm{l} / \mathrm{h})$ provides continuous infusion for 14 days. Images were taken at weeks 2 and 3 by BLI.

\section{Bioluminescence Imaging (BLI)}

In vivo imaging of luciferase-expressing tumor cells is a useful tool to investigate the dynamics of tumor growth and efficacy of anticancer treatment in living animal models. Bioluminescence, the conversion of chemical energy into light in living organisms, is dependent on two principal components, an enzyme luciferase and the substrate D-luciferin. The enzyme and substrate coupling in the presence of oxygen causes photon-releasing chemical reactions, and the emitted light, having an emission spectra ranging from 400 to $620 \mathrm{~nm}$, can be recorded quantitatively by a cooled charge-coupled (CCD) camera. The low background of luminescence from normal tissue, the rapid turnover of the luciferase enzyme, and 
the nonimmunogenic characteristics of luciferin make this method ideally suited for in vivo imaging [Soling and Rainov, 2003; Day et al., 2004]

$$
\begin{gathered}
\text { ATP }+\mathrm{D}-\text { luciferin }+\mathrm{O}_{2} \stackrel{\text { Luciferase }}{\longrightarrow} \text { Oxyluciferin }+ \\
\mathrm{AMP}+\mathrm{Ppi}+\mathrm{CO}_{2}+\text { light }
\end{gathered}
$$

Treated and untreated control groups were imaged weekly allowing a temporal assessment of in vivo tumor growth. This longitudinal study design permitted an accurate, real-time evaluation of tumor burden in the same animals over time. The light-sensitive substrate, Dluciferin (Biosynth International, Inc.) was kept at $4{ }^{\circ} \mathrm{C}$ in the dark and given by intraperitoneal or subcutaneous injection $(150 \mathrm{mg} / \mathrm{kg})$ from a $25 \mathrm{mg} / \mathrm{ml}$ stock solution in phosphate-buffered saline. The images were taken $8-10$ min after the D-luciferin injection, mice were placed under the CCD camera, and were kept under isoflurane anesthesia (1.5-2.0\%) during imaging. With the use of computer image analyses software (Igor Pro, WaveMetric, Inc.), color images of the tumor overlaid upon a picture of the particular mouse are created. Relative intensities of transmitted light were represented as a pseudo-color image ranging from blue (least intense) to red (most intense).

\section{RESULTS}

The in vitro effects of RX-0047, a HIF- $1 \alpha$ inhibitor, were evaluated on pancreatic (Panc1), breast (MDA-MB-231, HME50-T), prostate (PC-3), and lung (A549) cancer cell lines. Additionally in vivo effects of RX-0047 were determined in an experimental lung metastasis model and an intraperitoneal flank tumor model by bioluminesence imaging (BLI). As shown in Figure 1, all cell lines were sensitive to inhibition of cell growth with $10 \mathrm{nM}$ and higher concentrations of RX-0047. $\mathrm{IC}_{50}$ values of the cell lines are given in Table I. RX-0047 both inhibits cell proliferation and induce cell death; as the cells die, they usually lose adherence from

TABLE I. IC $_{50}$ Values of Different Cell Lines

\begin{tabular}{lc}
\hline Cell line & $\mathrm{IC}_{50}(\mathrm{nM})$ \\
\hline MDA-MB-231 & 4.00 \\
HME50-T & 2.90 \\
PC-3 & 2.60 \\
PANC-1 & 1.50 \\
A549 & 1.90 \\
\hline
\end{tabular}

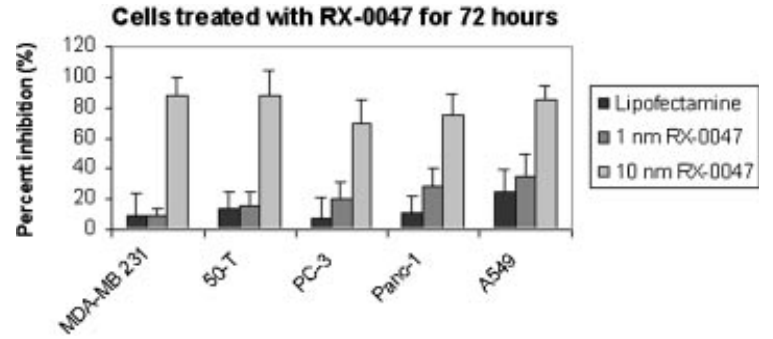

Fig. 1. Different doses of RX-0047 in human cancer cell lines. Cells were incubated with $1 \mathrm{nM}$ and $10 \mathrm{~nm}$ RX-0047 using Lipofectamine. After $72 \mathrm{~h}$ of incubation under hypoxic conditions at $37^{\circ} \mathrm{C}$, cells were counted and the percent inhibition was calculated. Lipofectamine alone (no drug) was used as a control.

the cell culture dish. To determine if RX-0047 shows sequence specificity to HIF- $1 \alpha$ mRNA; RX-0047, sense and mismatch control oligonucleotides were used to transfect UMRC2 cells. HIF-1 mRNA level was measured by RT-PCR analysis. The sense and mismatch controls did not affect HIF-1 $\alpha$ mRNA demonstrating the sequence-specific effects of RX-0047 on HIF-1 $\alpha$ expression (Fig. 2).

RT-PCR analysis showed that RX-0047 decreases HIF-1 mRNA expression compared to the controls in A549, PC-3 and PANC-1 cell lines (Fig. 3A). Additionally, we showed that HIF-1 protein expression was significantly decreased by RX-0047 especially in A549 and PC-3 cells by Western blot analysis (Fig. 3B).

To assess the effects of combination therapy of RX-0047 and irradiation, MDA-MB-231, HME50-T, PC-3 and A549 cells were treated with RX-0047. We chose the dose of RX-0047 and irradiation based on dose responses that were done with increasing RX-0047 amounts and increasing irradiation doses on all cell lines

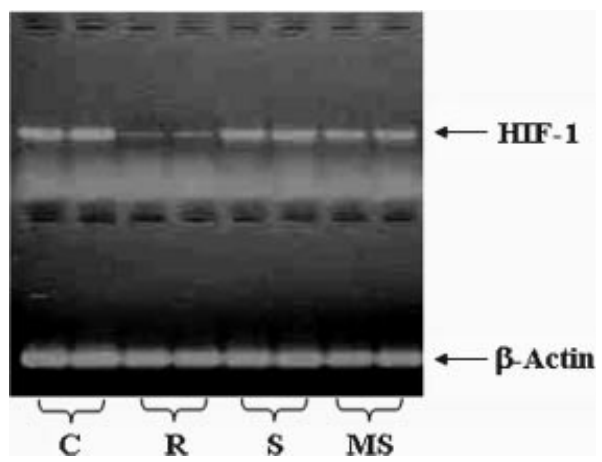

Fig. 2. RX-0047 shows sequence specificity in inhibiting HIF-1 mRNA expression in UMRC2 cells. C: Control, R: RX-0047, S: sense sequence of RX-0047 (control), MS: mismatch sequence of RX-0047 (control). 

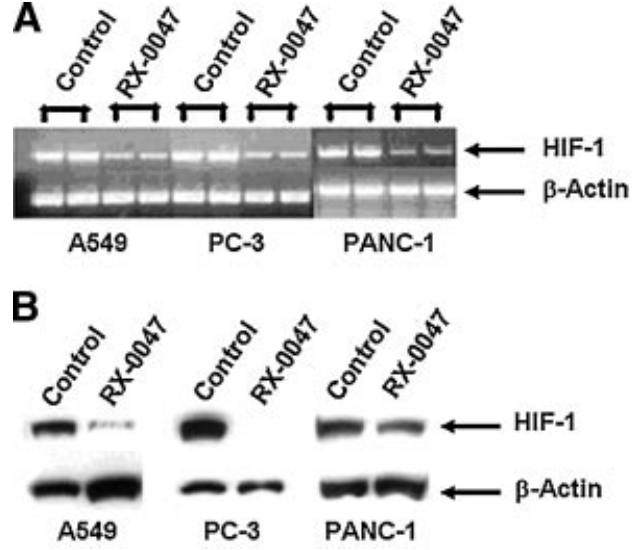

Fig. 3. The in vitro effects of RX-0047 in various human cancer cell lines. A: HIF-1 mRNA expression by RT-PCR. B: HIF-1 protein expression by Western blotting.

(data not shown). The combination of RX-0047 (5 nM) and gamma irradiation (2 Gy) increased the percent inhibition ratio of all cells except the PC-3 line, which was already so sensitive to 5 $\mathrm{nm}$ RX-0047 that the combinatorial effects could not be determined (Fig. 4). These in vitro results suggest that RX-0047 may be a potent anti-cancer agent and led to the design of our in vivo studies.

To test the in vivo effectiveness of RX-0047 in mice bearing A549 tumors, implantation of A549-Luc cells $\left(1 \times 10^{6}\right)$ via tail vein injection was performed. Animals in the treatment group were treated with $30 \mathrm{mg} / \mathrm{kg} /$ day for 2 weeks, and weekly in vivo images were taken from both untreated and treated animals. Two weeks after tail vein injection, A549-Luc cells produced metastases in the lungs of all four control animals whereas the four animals treated with RX-0047 $(30 \mathrm{mg} / \mathrm{kg}$ by IP injection, 14 consecutive days) showed minimal or no signal by BLI (two representative animals from each group are shown) (Fig. 5A). Drug treatment was then discontinued for 7 days to determine if lung metastasis would develop from residual cells. The control animals $(\mathrm{n}=4)$ showed higher signal compared to the previous week's imaging and the treated group began to show low signals as a result of the cessation of treatment and growth of residual tumor cells (Fig. 5B). Ex vivo imaging of excised lung lobes confirmed the in vivo bioluminescence signals. The frequency and size of metastatic lesions in lungs of the controls and the treatment groups are shown in Figure 6A-C. The tumor metastases appear as white nodules on the black lung surfaces after fixation in Fekete's solution.

BLI was also used for imaging of the flank tumors formed by PC-3-Luc cells. The treatment group was injected with RX-0047 (30 mg/ $\mathrm{kg}$ ) for 2 weeks via Alzet osmotic pump inserted intraperitoneally whereas the controls were not treated. The treatment reduced the formation of flank tumors on each side compared to the control group (Fig. 7A,B).

\section{DISCUSSION}

Due to considerable links between HIF-1 $1 \alpha$ and cancer, a variety of approaches are being tested to inhibit the HIF- $1 \alpha$ pathway that include small molecule inhibitors, peptides, antisense technology and gene therapy [Sun et al., 2001; Rapisarda et al., 2002]. A number of anti-cancer agents have been reported to

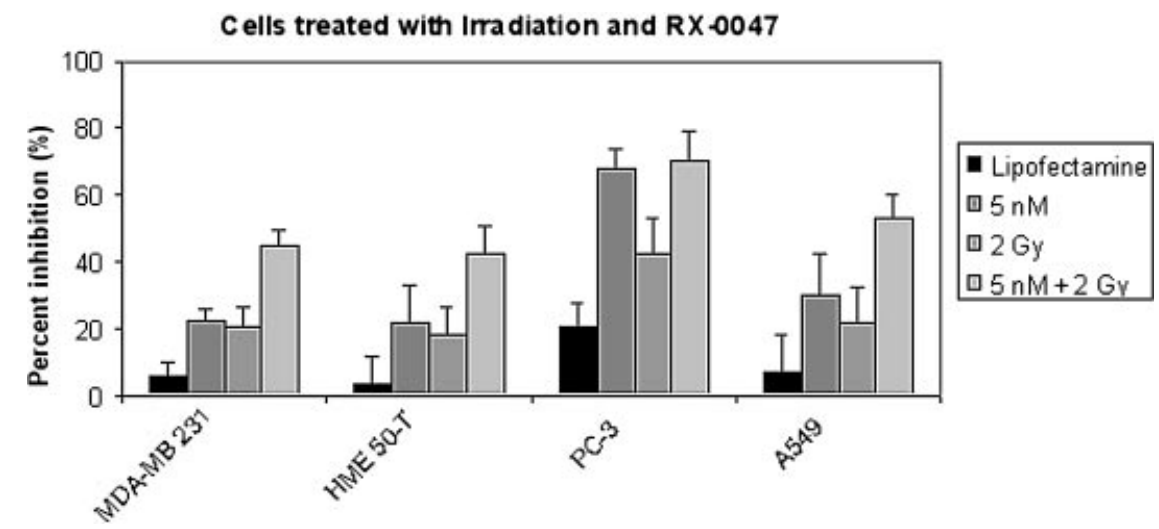

Fig. 4. The effect of RX-0047 and irradiation combination therapy. Cells were incubated with $5 \mathrm{nM} R X-$ 0047 using Lipofectamine 2000 for $4 \mathrm{~h}$. Media was then removed, and fresh media without the drug was added. Cells were then treated with 2 Gy gamma irradiation. After 3 days of incubation, cells were counted and the percent inhibition was calculated. Lipofectamine alone (no drug) was used as a control. 

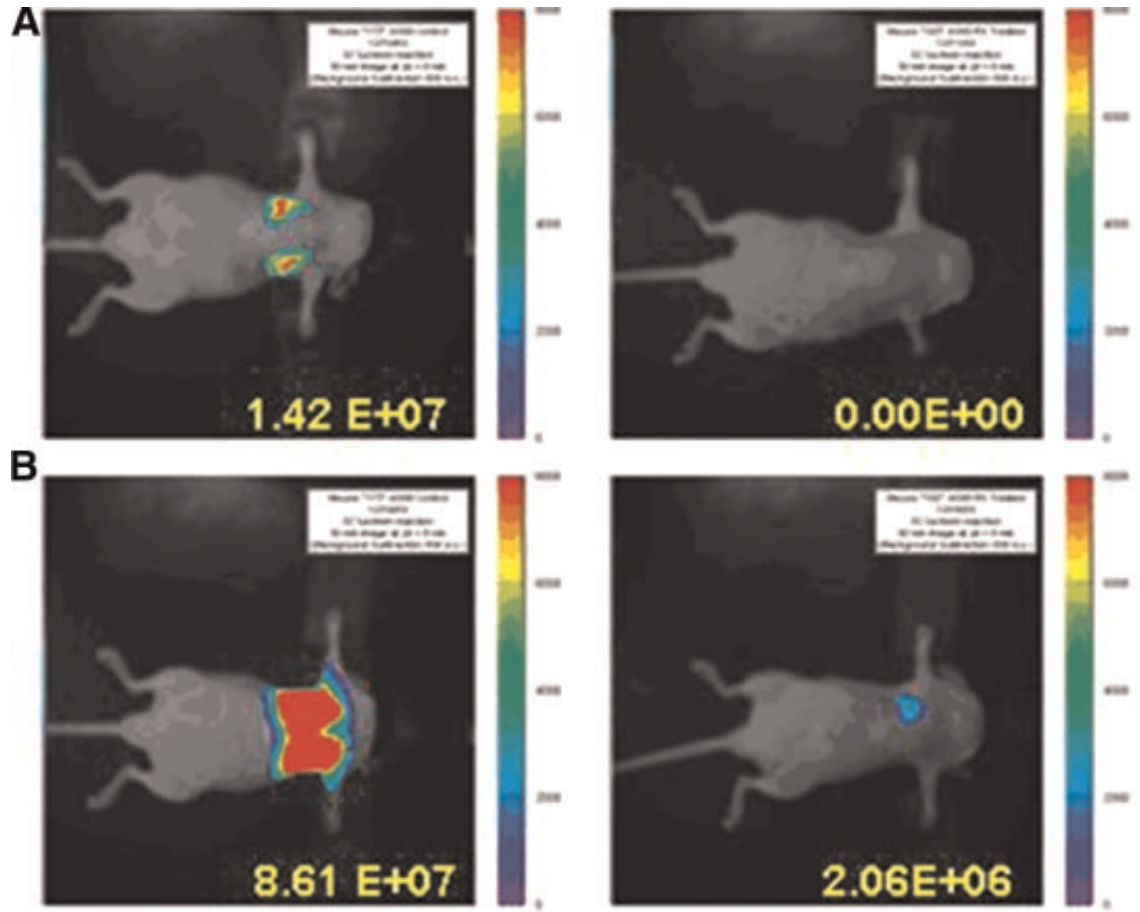

Fig. 5. The in vivo effects of RX-0047 treatment on A549-Luc cells. A: Two weeks after tail vein injection of A549-Luc cells $\left(1 \times 10^{6}\right)$. The image on the left is the control and on the right side 2 weeks treatment with RX$0047(30 \mathrm{mg} / \mathrm{kg} /$ day, intraperitoneal injection, 14 days). B: Three weeks after tail vein injection of A549-Luc cells $\left(1 \times 10^{6}\right)$. The image on the left hand is the control and the image on the right hand is 7 days after the end of RX-0047 treatment. [Color figure can be viewed in the online issue, which is available at www. interscience.wiley.com.]

decrease HIF-1 $\alpha$ activity in cells in culture such as Hsp-90 inhibitors (radicicol, geldanamycin), antimicrotubule agents (taxol, vincristine), topoisomerase inhibitors (topotecan, GL331), histone deacetylase inhibitors (FK228), thioredoxin inhibitors (PX-12) and MEK1 inhibitors (PD98059); however, only a few of the reported HIF-1 $\alpha$ inhibitors demonstrated antitumor activity in vivo [Powis and Kirkpatrick, 2004; Patiar and Harris, 2006].

In this study, we tested the in vitro and in vivo effects of RX-0047, an antisense oligonucleotide HIF-1 $\alpha$ inhibitor, in different cancer cell lines. First, we examined tumor cell growth inhibition

A

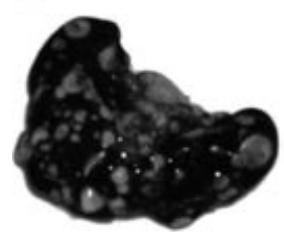

B

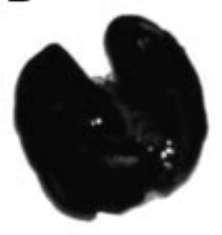

due to RX-0047 treatment and our results showed that RX-0047 is cytotoxic in vitro against various cancer cell types in nanomolar concentrations. HME50-T, MDA-MB-231, Panc1, PC-3 and A549 cancer cell lines were found to be sensitive to inhibition of cell growth with $10 \mathrm{nM}$ and higher concentrations of RX-0047. The results indicate that the actions are distinct and differ according to the cellular background and suggest that these differences are important in tumor development.

It has been frequently reported that hypoxic conditions and the elevated level of HIF-1 $\alpha$ in tumor tissues are associated with resistance of tumor cells to radiotherapy [Aebersold et al., 2001; Sasabe et al., 2007]. Although the precise mechanism of the hypoxia-induced radioresistance of tumor cells is not fully known, Moeller et al. [2004] has claimed that after irradiation, during reoxygenation, free radical species accumulate in tumor tissue and lead to overexpression of HIF-1. Interestingly, dose-dependent increases in HIF-1 activity was observed approximately $12-24 \mathrm{~h}$ after radiation at the tumor periphery first and then migrated toward the center of the tumor between 24 and $48 \mathrm{~h}$.
Fig. 6. The ex vivo staining of lung metastases with india ink. A Control group. B: RX-0047 treatment group $(30 \mathrm{mg} / \mathrm{kg} /$ day, intraperitoneal injection, for 14 days). C: 7 days after cessation of RX-0047 treatment.

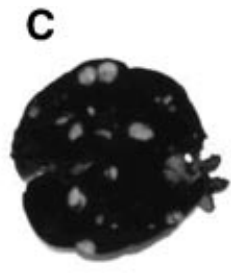



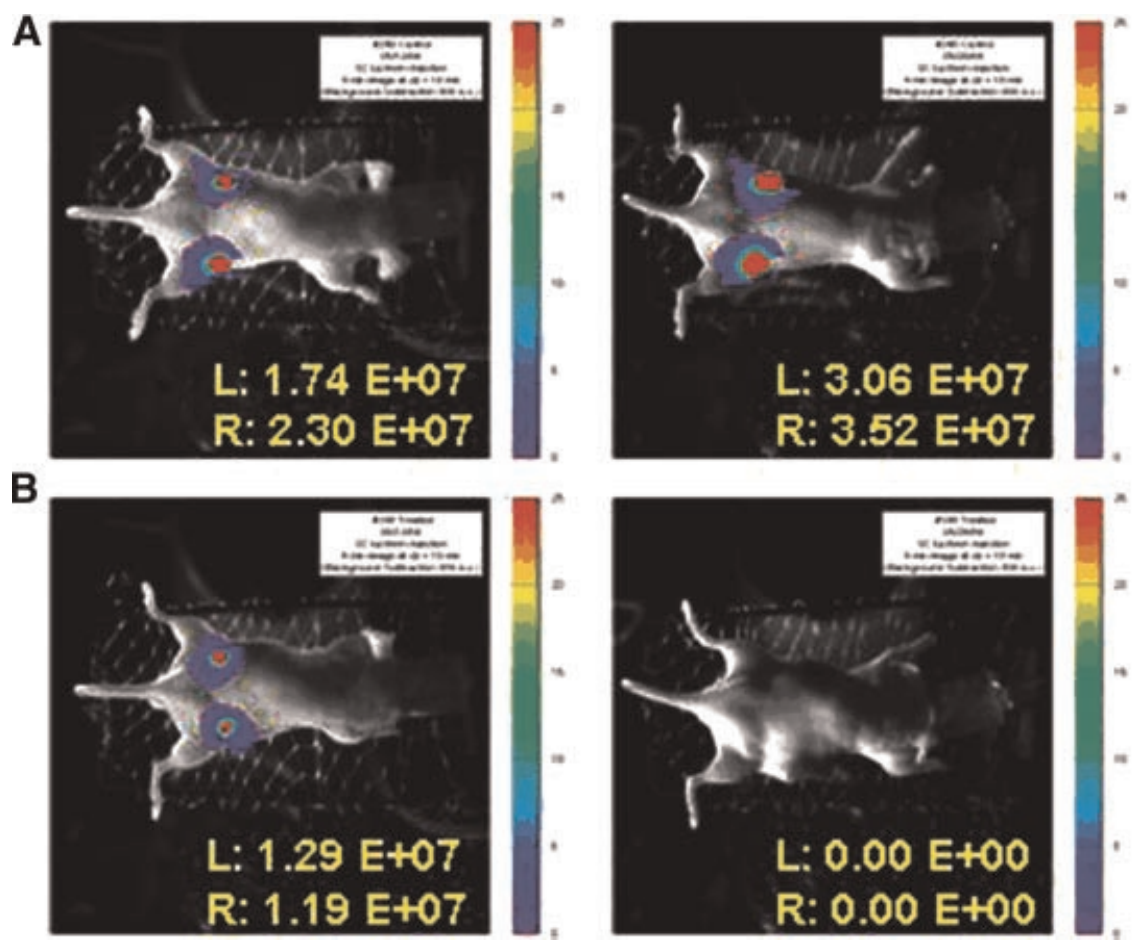

Fig. 7. The in vivo effects of RX-0047 treatment on PC-3-Luc cells. A: Control group: The image on the left is 2 weeks after the injection of PC-3-Luc cells and the image on the right is 3 weeks after the injection of cells. B: RX-0047 treatment group (30 mg/kg with Alzet ${ }^{\mathbb{R}}$ osmotic pump): The image on the left hand is after RX-0047 treatment for 2 weeks. The image on the right hand is 1 week after the end of the treatment. [Color figure can be viewed in the online issue, which is available at www.interscience.wiley.com.]

Additionally, they also showed that HIF-1 upregulation promotes the secretion of proangiogenic cytokines such as VEGF and FGF which are known to promote endothelial cell survival and increase radioresistance. Furthermore HIF-1 deficient tumors are found to be more radiosensitive than their wild-type counterparts [Moeller et al., 2005]. Therefore, it has been suggested that HIF-1 is a rational target for tumor radiosensitization.

In our study, we first treated the cells with HIF- $1 \alpha$ inhibitor, RX-0047, then we irradiated in order to maximize radiosensitivity. The combinations of RX-0047 (5 nM) and gamma irradiation (2 Gy) caused an additive effect and increased the percent inhibition ratio of MDAMB-231, HME50-T and A549 cells. As irradiation and the drug worked more effectively together than either used alone, we suggest that RX-0047 may be a reversing agent for radiation resistance and thus may be an option for patients with radiotherapy (RT) resistant tumors. However, the efficacy of combined RT and HIF-1 inhibition may vary from tumor to tumor, but proper timing of HIF-1 blockade could optimize its effects on radiotherapy.
Additionally, our in vivo data showed that RX-0047 inhibited tumor formation of the PC-3Luc cells in flank tumor model and effectively prevented lung metastasis in nude mice with intravenously introduced cells. However, 1 week after the end of the treatment, formation of lung metastases were detected via BLI. A longer treatment period may be even more effective to durably inhibit the formation of lung metastasis. Alternatively, the residual cells after RX-0047 treatment that are not being affected may not be hypoxic but may be sensitive to other treatments such as chemotherapy or radiotherapy. Furthermore, the flank tumors were treated continuously using osmotic pumps whereas the lung tumors were treated by IP injection every 3 days. Therefore, it is possible that treatment with the osmotic pump (e.g., continuous infusion) versus IP injection every 3 days might have been more effective, resulting in total loss of signal. As a result, we conclude that RX-0047 is an effective anti-cancer drug, particularly in a human lung cancer and prostate cancer model, and warrants further investigation that may lead to the design of human Phase I clinical trials. 
HIF-1 expression levels and hypoxia are important determinants how tumor radiosensitivity will respond to HIF-1 blockade. Hypoxic tumors showing HIF-1 $\alpha$ expression levels may respond best to this type of treatment. Therefore, methods of identifying tumors with high hypoxic fractions could be useful in selecting patients who will benefit from HIF-1 blockade during chemo/radiotherapy [Moeller et al., 2005; Moeller and Dewhirst, 2006].

However, it remains an important yet unresolved issue to determine whether inhibiting the function of HIF-1 in normal tissues would impair their ability to recover from radiation damage therapy. As HIF-1 is not typically active in most healthy normal tissues except the liver and thymus, it is not expected that its inhibition would seriously affect normal tissue radiosensitivity [Moeller and Dewhirst, 2006]. Understanding the role of HIF- $1 \alpha$ in cancer and the molecular mechanisms leading to its activation will hopefully provide testable models for the treatment of cancers and tumors that perturb the HIF- $1 \alpha$ signaling pathway. Our preclinical results should help in the design of human clinical trials for the combination therapy of cancer using RX-0047.

\section{ACKNOWLEDGMENTS}

We are grateful to Cancer imaging group (Ralph Mason, Peter Antich, Edmond Richer, Bob Bollinger, Allen Harper) of the University of Texas Southwestern Medical Center for assistance with technical development. This research was supported by the research fund from the UT Southwestern/MD Anderson Lung SPORE CA70907, the Cancer Imaging Program P20 (pre-ICMIC) CA 86354, TUBITAK (The Scientific and Technical Research Council of Turkey), TEV (Turkish Education Foundation), and Rexahn Pharmaceuticals, Inc., Rockville, Maryland. This study was carried out at the University of Texas Southwestern, Department of Cell Biology and Simmons Comprehensive Cancer Center Imaging Center.

\section{REFERENCES}

Aebersold DM, Burri P, Beer KT, Laissue J, Djonov V, Greiner RH, Semenza GL. 2001. Expression of hypoxiainducible factor-1alpha: A novel predictive and prognostic parameter in the radiotherapy of oropharyngeal cancer. Cancer Res 61(7):2911-2916.
Akakura N, Kobayashi M, Horiuchi I, Suzuki A, Wang J, Chen J, Niizeki H, Kawamura Ki, Hosokawa M, Asaka M. 2001. Constitutive expression of hypoxia-inducible factor-1alpha renders pancreatic cancer cells resistant to apoptosis induced by hypoxia and nutrient deprivation. Cancer Res 61(17):6548-6554.

Birner P, Schindl M, Obermair A, Plank C, Breitenecker G, Oberhuber G. 2000. Overexpression of hypoxia-inducible factor 1alpha is a marker for an unfavorable prognosis in early-stage invasive cervical cancer. Cancer Res 60(17):4693-4696.

Bos R, Zhong H, Hanrahan CF, Mommers EC, Semenza GL, Pinedo HM, Abeloff MD, Simons JW, Van Diest PJ, Van der Wall E. 2001. Levels of hypoxia-inducible factor1 alpha during breast carcinogenesis. J Natl Cancer Inst 93(4):309-314.

Bracken CP, Whitelaw ML, Peet DJ. 2003. The hypoxiainducible factors: Key transcriptional regulators of hypoxic responses. Cell Mol Life Sci 60(7):1376-1393.

Bruick RK. 2003. Oxygen sensing in the hypoxic response pathway: Regulation of the hypoxia-inducible transcription factor. Genes Dev 17(21):2614-2623.

Day JC, Tisi LC, Bailey MJ. 2004. Evolution of beetle bioluminescence: The origin of beetle luciferin. Luminescence 19(1):8-20.

Giatromanolaki A, Koukourakis MI, Sivridis E, Turley H, Talks K, Pezzella F, Gatter KC, Harris AL. 2001. Relation of hypoxia inducible factor 1 alpha and 2 alpha in operable non-small cell lung cancer to angiogenic/ molecular profile of tumours and survival. $\mathrm{Br} \mathrm{J}$ Cancer 85(6):881-890.

Goda N, Dozier SJ, Johnson RS. 2003. HIF-1 in cell cycle regulation, apoptosis and tumor progression. Antioxid Redox Signal 5(4):467-473.

Ivan M, Kondo K, Yang H, Kim W, Valiando J, Ohh M, Salic A, Asara JM, Lane WS, Kaelin WG, Jr. 2001. HIF-alpha targeted for VHL mediated destruction by proline hydroxylation: Implications for $\mathrm{O} 2$ sensing. Science 292(5516):464-468.

Maxwell PH, Wiesener MS, Chang GW, Clifford SC, Vaux EC, Cockman ME, Wykoff CC, Pugh CW, Maher ER, Ratcliffe PJ. 1999. The tumour suppressor protein VHL targets hypoxia-inducible factors for oxygen-dependent proteolysis. Nature 399(6733):271-275.

Moeller BJ, Dewhirst MW. 2006. HIF-1 and tumour radiosensitivity. Br J Cancer 95(1):1-5.

Moeller BJ, Cao Y, Li CY, Dewhirst MW. 2004. Radiation activates HIF-1 to regulate vascular radiosensitivity in tumors: Role of reoxygenation, free radicals, and stress granules. Cancer Cell 5(5):429-441.

Moeller BJ, Dreher MR, Rabbani ZN, Schroeder T, Cao Y, Li CY, Dewhirst MW. 2005. Pleiotropic effects of HIF-1 blockade on tumor radiosensitivity. Cancer Cell 8(2):99110.

Patiar S, Harris AL. 2006. Role of hypoxia-inducible factor$1 \alpha$ as a cancer therapy target. Endocr Relat Cancer 13:61-75.

Powis G, Kirkpatrick L. 2004. Hypoxia inducible factor-1A as a cancer drug target. Mol Cancer Ther 3(5):647-654.

Rapisarda A, Uranchimeg B, Scudiero DA, Selby M, Sausville EA, Shoemaker RH, Melillo G. 2002. Identification of small molecule inhibitors of hypoxia-inducible factor-1 transcriptional activation pathway. Cancer Res 62(15):4316-4324. 
Salceda S, Caro J. 1997. Hypoxia-inducible factor-1a (HIF$1 \alpha$ ) protein is rapidly degraded by the ubiquitin-proteasome system under normoxic conditions. J Biol Chem 272:22642-22647.

Sasabe E, Zhou X, Li D, Oku N, Yamamoto T, Osaki T. 2007. The involvement of hypoxia-inducible factor-1 a in the susceptibility to $\gamma$-rays and chemotherapeutic drugs of oral squamous cell carcinoma cells Int. J Cancer 120(2):268-277.

Semenza GL. 2000. HIF-1 and human disease: One highly involved factor. Genes Dev 14(16):1983-1991.

Semenza GL. 2002. Involvement of hypoxia-inducible factor 1 in human cancer. Intern Med 41(2):79-83.

Semenza GL, Nejfelt MK, Chi SM, Antonarakis SE. 1991. Hypoxia-inducible nuclear factors bind to an enhancer element located $3^{\prime}$ to the human erythropoietin gene. Proc Natl Acad Sci USA 88:5680-5684.

Shannon AM, Bouchier-Hayes DJ, Condron CM, Toomey D. 2003. Tumour hypoxia, chemotherapeutic resistance and hypoxia-related therapies. Cancer Treat Rev 29(4):297307.

Soling A, Rainov NG. 2003. Bioluminescence imaging in vivo application to cancer research. Expert Opin Biol Ther 3:1163-1172.

Stewart M, Talks K, Leek R, Turley H, Pezzella F, Harris A, Gatter K. 2002. Expression of angiogenic factors and hypoxia inducible factors HIF 1 , HIF 2 and CA IX in nonHodgkin's lymphoma. Histopathology 40(3):253-260.
Sun X, Kanwar JR, Leung E, Lehnert K, Wang D, Krissansen GW. 2001. Gene transfer of antisense hypoxia-inducible factor- $1 \alpha$ enhances the therapeutic efficacy of cancer immunotherapy. Gene Ther 8(8):638645.

Wang GL, Semenza GL. 1995. Purification and characterisation of hypoxia-inducible factor-1. J Biol Chem 270(3):1230-1237.

Wang GL, Jiang BH, Rue EA, Semenza GL. 1995. Hypoxiainducible factor- 1 is a basic-helix-loop-helix-PAS heterodimer regulated by cellular $\mathrm{O}_{2}$ tension. Proc Natl Acad Sci USA 92(12):5510-5514.

Wright WE, Shay JW. 2006. Inexpensive low-oxygen incubators. Nat Protoc 1(4):2088-2090.

Xia G, Kageyama Y, Hayashi T, Hyochi N, Kawakami S, Kihara K. 2002. Positive expression of HIF-2alpha/ EPAS1 in invasive bladder cancer. Urology 59(5):774778.

Zagzag D, Friedlander DR, Margolis B, Grumet M, Semenza GL, Zhong H, Simons JW, Holash J, Wiegand SJ, Yancopoulos GD. 2000. Molecular events implicated in brain tumor angiogenesis and invasion. Pediatr Neurosurg 33:49-55.

Zhong H, De Marzo AM, Laughner E, Lim M, Hilton DA, Zagzag D, Buechler P, Isaacs WB, Semenza GL, Simons JW. 1999. Overexpression of hypoxia-inducible factor- $1 \alpha$ in common human cancers and their metastases. Cancer Res 59(22):5830-5835. 